\title{
Factors Related Work Load Stress Among Migrant Semi-Skilled Workers in Messaieed Qatar
}

\section{Zaenal Mutaqin'}

1 Messaieed Medical Center Qatar Petroleum

\section{Article Info}

\section{Article History: \\ Accepted May 7th, 2019}

\section{Key words:}

Stress; Stressors; Migrant Semi-Skilled Workers

\section{INTRODUCTION}

Stress is a very popular terminology and is an inevitable thing in human life. Every person has experienced and will experience it with different levels depending on the physical and psychological resistance of the individual. This is the influence of fast-changing social changes as a consequence of

Corresponding author:

Zaenal Mutaqin

zaenal_mutaqin77@yahoo.com

South East Asia Nursing Research, Vol 1 No 1, June 2019

ISSN:2685-032X

DOI: https://doi.org/10.26714/seanr.1.1.2019.27-36 modernization,

industrialization, advancement of science, and technology that has influenced moral, ethical, and lifestyle values, where not everyone is able to adapt, depending on personality owned by each individual. ${ }^{1}$

Stress arises due to the gap between the demands generated by transactions between individuals and the environment 
with biological, psychological or social systems possessed by these individuals that will affect their cognition, emotions, and social behavior. ${ }^{2}$ Stress caused by environmental and social physical conditions in the form of situations, events, or objects that cause demands in the body and cause psychological reactions called stressors. $^{3}$

The State of Qatar is a small country in the Middle East region, in the form of a peninsula which consists mainly of deserts and beaches with a length of about $60 \mathrm{~km}$. Compared to Indonesia in the tropics, Qatar has many differences including: Geographical conditions that are mostly composed of barren deserts and beaches, extreme climates where temperatures will reach $50^{\circ} \mathrm{C}$ during summer and $5^{\circ} \mathrm{C}$ in winter, the use of English as a second language and language in the world of work and academics, cultural social life is diverse because this country is one of the countries in the Middle East (Middle East) which is used as a destination country to find work by migrant workers (migrant workers destination country) from various countries in the world, physical and psychological conditions of competitive work, and enforcement of state regulations and laws based on Islamic teachings, and other differences. The differences above can lead to stress on migrants or workers in this country.

The Indonesian population in Messaaieed, one of the provinces in Qatar is divided into two, most of which are in the housing complex of oil and gas companies, and the others are in camps for workers labor camp). Indonesian residents who work in the professional sector at Messaieed are working for various oil and gas companies, while those who work as semi-skilled workers work for contracting companies that support and support the operations of oil and gas companies.

Workers in the semi skill and unskill sectors, they only get work visa facilities with a bachelor contract status, which means they do not get family visa facilities. In addition, they also have to live in "labor camp" together with thousands of other semi-skill and non-skill workers. This condition at least raises a variety of problems both in terms of health, social interaction relationships, and certainly has the potential to create interpersonal relationship conflicts between those who can cause stress.

Stress on Indonesian semi-skilled migrant workers in Qatar occurs a lot and can cause anxiety. Stress that is felt can interfere with the role and function of the worker both in his work or in his daily life. The stress felt by Indonesian semi-skilled migrant workers in Messaieed Qatar can come from oneself (internal) or from outside (external). The stressors need to be identified so that they can be controlled or minimized and modifications to the condition are made to reduce them.

Based on interviews conducted by the author of 5 Indonesian migrant semi-skill workers who work and live in Messaieed Qatar, found factors that have the potential to trigger stress and depression if prevention is not carried out and modification of existing conditions properly and correctly. The results of the interview stated that all respondents stated that they did not feel comfortable living in Qatar, all respondents mentioned internal factors (far from families in Indonesia) as stressors, 4 people (80\%) mentioned occupational factors as stressors, 4 people $(80 \%)$ mentioned extreme temperatures as a stressor, and 3 people (60\%) mentioned a factor in their lack of ability to adapt to people other than Indonesia due to a lack of ability to speak English. Based on the description above, both from the results of interviews or the facts and phenomena of differences that exist in Qatar, it is necessary to examine whether the factors behind the stress of migrant semi skill workers at Messaieed Qatar. For this reason, researchers are interested in 
conducting research to find out and identify what factors are related to stress on Indonesian migrant semi-skilled workers in the Qatar Messaieed region.

\section{METHODS}

This type of research uses descriptive analytical study methods, this study aims to determine stress-related factors in Indonesian semi-skilled migrant workers in the Qatar Messaieed region. The research design used is a cross-sectional study where observations of research samples are only done once in a certain period or period. The method used in this study is a survey by conducting interviews and distributing questionnaires to respondents. The population in this study were all Indonesian semi-skilled migrant workers who were in the Qatar Messaieed region with around 80 people. Sampling in this study was carried out by the total sampling method, namely taking all the population with the inclusion criteria, respondents who were between 20 and 50 years old, willing to be respondents, were at the location when the study was conducted. Data collection tool using a questionnaire that has been tested before.

The collected data were analyzed univariate with the aim to explain or describe the characteristics of each research variable, and bivariate which aims to determine the relationship between the dependent variables namely stress level with each independent variable namely physical condition, psychological burden, extreme weather, workload, and environmental conditions of residence. The test used is the Pearson Correlation because the data is normally distributed.

\section{RESULTS}

This research was conducted in December 2011 to April 2012, located in the Indonesian community in the Qatar Messaieed region. The number of respondents in this study was 70 people with all respondents being male. Of all 70 questionnaires distributed to respondents, all were filled out because the researchers accompanied the respondents at the time of filling out the questionnaire.

The distribution of respondents based on age found the youngest age of respondents was 21 years, and the oldest age was 55 years with an average age of respondents was 34.5 years, while the highest number was in the age group 31-40 years as many as 26 people (37.14\%). Based on the level of education shows that the majority of respondents as many as 29 people $(41.45 \%)$ have a high school education, and at least are elementary school educated as many as 12 people $(17.1 \%)$. Based on the type of work obtained, most of the respondents, as many as 36 people (51.45\%) worked as drivers, while the others worked as laborers (labor/rigger) as many as 17 people $(24.3 \%)$ and other jobs (welder, pipe fitter, foreman). Based on marital status most of the respondents were married as many as 55 people (78.6\%), and the rest were still single, 15 people (21.4\%). Meanwhile, based on the tenure of respondents in Qatar, the average working period of respondents in Qatar was 2.36 years with the latest working period $<1$ year, while the longest working period was 7 years, with the highest working period of 1-3 years, which was 34 people $(48.6 \%)$.

The results of the study showed that most experienced severe stress as many as 36 people (51.4\%), while the rest experienced mild stress as many as 34 people (48.6\%). Most of the respondents' perceptions of their physical condition are in good condition as many as 40 people (57.1\%), the rest are in a bad condition as many as 30 people (42.9\%). Most of the respondents felt psychological burden stressors in the weight level as many as 38 people (54.3\%), while the rest were in the light level as many as 32 people $(45.7 \%)$. Most of the respondents felt that extreme weather stressors were in bad condition as 
many as 49 people (70\%), and only a small percentage felt it was good, 21 people $(30 \%)$. The results showed that the majority of respondents felt the condition of heavy workload as many as 36 people $(51.4 \%)$, and the rest felt it in mild conditions as many as 34 people (48.6\%). The results of the study also showed that the majority of respondents felt that the conditions of living conditions were in good condition as many as 43 people $(61.4 \%)$, and only a small proportion of those who perceived them in a bad condition were 27 people (39.6\%).

The results showed that there was a relationship between physical conditions and stress levels of respondents ( $p$-value of $0.000(<0.05)$ and the value of $r=0.407)$. Graph 1.1 illustrates the direction of the relationship between the variables of physical conditions and stress levels. The direction of a positive linear pattern relationship means that the better the physical condition of the respondent the lighter the stress level. The determinant coefficient of $16.6 \%$ means that the physical condition affects stress by $16.6 \%$, the remaining $73.4 \%$ is determined by other factors.

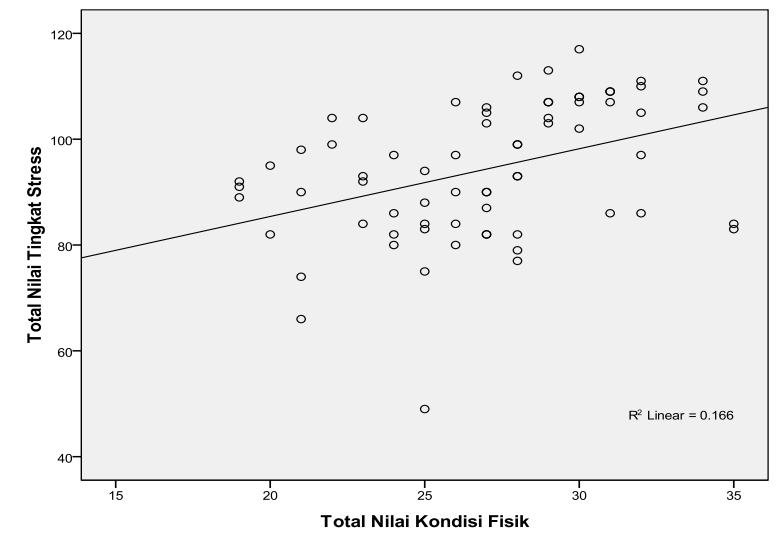

Figure 1

Correlation of stressors of physical conditions with stress levels in Indonesian migrant semi skill workers at Qatar Messaieed

The results of the study on the correlation of psychological burden stressors with stress levels on semi-skilled migrant workers are described in Figure 2.

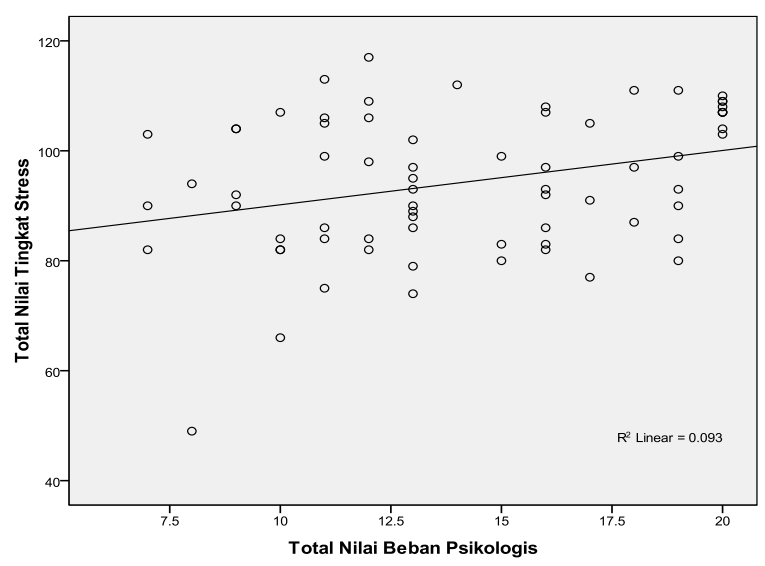

Figure 2

Scatter plot the correlation of psychological stress with stress levels in Indonesian migrant semi skill workers at Qatar Messaieed

Figure 2 shows that there is a significant relationship between psychological burden and stress level of respondents ( $p$-value of $0.010(<0.05)$ and $r=0.305)$. The direction of the relationship has a positive linear pattern means that the lighter the psychological burden of the respondent the lighter the stress level. The determinant coefficient of $9.3 \%$ means that the psychological burden affects stress by $9.3 \%$, the remaining $90.7 \%$ is determined by other factors.

The results showed that there was no relationship between extreme weather and stress levels of respondents ( $p$-value of 0.252 ( $>0.05$ ) and $r=0.139$ ). The results showed that there was a significant relationship between workload and stress level of respondents ( $p$-value of 0.001 $(<0.05)$ and $r=0.379)$. The direction of the relationship has a positive linear pattern, which means that the lighter the workload of respondents, the lighter the stress level. The determinant coefficient of $14.4 \%$ means that the workload affects stress by $14.4 \%$, the remaining $85.6 \%$ is determined by other factors.

The results of other studies on environmental conditions with stress 
levels of respondents are described in figure 3. The results showed that there was a significant relationship between living conditions and stress levels of respondents ( $p$-value of $0.000(<0.05)$ and $r=0.541)$. The direction of the relationship has a positive linear pattern, which means that the better the environmental conditions of respondent living, the lighter the stress level will be.

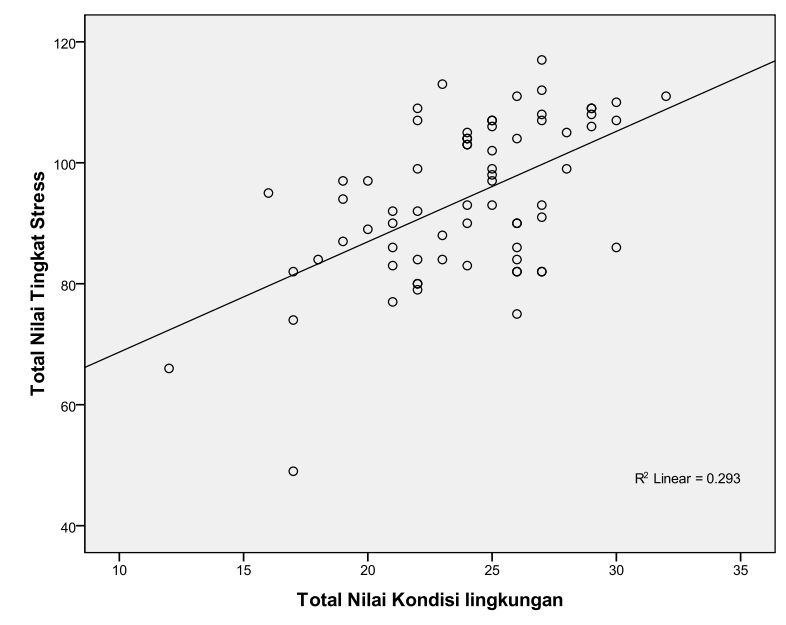

Figure 3

Scatter plot the correlation of environmental conditions with stress levels in Indonesian migrant semi skill workers in Qatar Messiah

The results of the study on figure 3 show the large determinant coefficient of $29.3 \%$, which means that the living conditions of the environment affect stress by $29.3 \%$, the remaining $70.7 \%$ is determined by other factors.

\section{DISCUSSION}

Based on the results of the study showed that the average age of the respondents was 34.5 years, the youngest age was 21 years while the oldest was 55 years. This is in accordance with the regulations of the Qatari government regarding the age limit for workers ranging from 20 to 60 years.

The results of the study also showed that the majority of respondents' education was high school as many as 29 people (41.45\%), junior high school educated as many as 29 people (41.45\%) and the rest had elementary education, 12 people (17.1\%). The company regulations that employ them require a minimum education of High School or Middle / High School, but in reality, there are 12 workers with elementary education who can pass the selection to work in Qatar. The level of education of a person is very influential on the ability and performance of his work, especially it will have an effect on his ability to manage the stress he finds when working.

Based on the type of work, the results showed that the majority of respondents worked as drivers (drivers for large vehicles, such as: employee buses, dump trucks, and long haul trucks / tronton) as many as 36 people (51.4\%), who worked as laborers (labor / rigger spread in various divisions such as canteen, construction, oil and gas project, and bridge / road construction) as many as 17 people $(24.3 \%)$, and worked in other sectors (Pipe fitter, welder, foreman) as many as 17 people $(24.3 \%)$. Determination of semi-skilled workers is in accordance with the criteria set another study which divides the type of worker into three, consisting of Non-Skilled workers, Semiskilled workers, and Skilled / Professional workers.

Most of the respondents were married to 55 people $(78.6 \%)$, meaning that the respondents had a greater risk of being exposed to stress because they were separated from their families. Their biological needs certainly get a nuisance because the leave provided by the company is given at least annually. According to the hierarchy of needs established by Abraham Maslow biological and physiological needs are the most basic in the pyramid. one of the basic needs can influence other needs, including influencing the psychological condition and work. ${ }^{3}$

The results of the study also showed that the majority of respondents had a working period of 1-3 years, namely 34 people 
(48.6\%). However, there are 28 respondents $(40 \%)$ who have a working period of $<1$ year, this means that they are still adapting to the environment and the new work they are currently living. Even some people have just come to Qatar in less than 2 months. States that the source of stress can be in the form of bioecology such as drastic weather changes, extreme temperatures that can make individuals experience physical and psychological stress, and sources of psychosocial stress such as new jobs, and environment and community atmosphere the new one. ${ }^{4}$

Based on the results of the study showed that the majority of respondents as many as 36 people $(51.4 \%)$ had stress at a severe level. This can be seen from the frequency distribution of questionnaires which showed that as many as 50 people (71.43\%) answered sometimes feeling stiff when hanging out with coworkers and their environment, 46 people (65.71\%) answered sometimes losing their appetite, 45 people (64.29\%) answer sometimes disagree with colleagues / supervisors, and 42 people $(60 \%)$ answer sometimes feel bored/bored with their jobs. In fact, there were 19 people (27.4\%) who answered always and often thumped when communicating with superiors and 21 people (30\%) who answered always and often felt disappointed with the treatment of superiors.

The results of this study are in line with the other research, the results of his research show this result is influenced by the company's target that is too high, limited time in completing work, lack of adequate responsibility from the company, heavy workload, and ambiguity role in work. The high level of stress experienced by respondents can occur because the education level of respondents on average is still lacking. The level of education of a person is very influential on the ability and performance in work, especially in managing the stress he finds when working. The severe stress experienced by respondents needs to be given serious attention and needs to be addressed because if it does not interfere. 5,6

The results showed that as many as 30 people $(42.9 \%)$ stated that their physical condition was in bad condition. There were 36 people $(51.42 \%)$ who said that since coming to Qatar their sexual needs were often and always disturbed. This is understandable because most of the respondents were 55 people $(78.6 \%)$ who were married and lived far from their wives and families. In addition, as many as 18 people $(25.52 \%)$ consumption of smoking has increased, and as many as 17 people (24.29\%) have disturbed sleep patterns.

Stress has an impact on physical, psychological, health, cognition and organization including being easily saturated and bored, having difficulty resting, and experiencing sleep disorders. This is also in accordance with the other study which states that the body will give a physical reaction to various challenges encountered in life by trying to harmonize it or that the individual will recover quickly enough with the influence of the experience of stress experienced before. ${ }^{7}$

The results showed that the majority of respondents as many as 38 people (54.3\%) stated that their psychological burden was severe. It is seen that as many as 38 people (54.28\%) often and always feel anxious/worried about the development of their children, 36 people (51.43\%) answered frequently and always felt anxious about their children's education, and as many as 22 people (31.43\%) say often and always feel anxious/worried about the loyalty of his wife. This is consistent with another statement that family conditions that are not good can cause a person's condition to become stressed with the burden, the condition of respondents who are far apart from their families shows that their family is in a bad condition. ${ }^{7}$ The above opinion is also 
supported by the opinion of Gottlieb which states that close and positive attachment to others, especially with family and friends, is consistently found as a good defense against stress. ${ }^{8}$

The results showed that most of the respondents were 49 people (70\%) stated that extreme weather conditions in Qatar were in bad condition. This can be seen from the frequency distribution of the questionnaire, of which from 5 questions / statements about extreme weather, where as many as 43 people (61.43\%) answered frequently and always felt uncomfortable with dust storms that often occur in Qatar, 39 people (55.72\%) answered often and always feel insecure when traveling in the midst of dust storms, as many as 39 people $(55.72 \%)$ answered frequently and always felt the summer weather in Qatar was too hot for them, and 37 people (52.86\%) answered always and often felt the temperature of the season the cold in Qatar is too cold for them.

The results showed that the majority of respondents, 36 people (51.4\%) stated that the workload was in heavy condition. This can be seen from the frequency distribution of the questionnaire, where out of 8 questions / statements about workload, where as many as 51 people $(72.86 \%)$ have to answer frequently and always be extra careful in doing their work, 32 people (45.72\%) answer frequently and always felt that the work was full of danger/risk, and as many as 29 people $(41.43 \%)$ answered frequently and always felt their superiors asked for work to be completed on time.

Work stress is caused by too many tasks, limited time, lack of responsibility, role ambiguity, value differences, frustration, changes in work types, and changes or role conflicts. ${ }^{9,10}$ The presence of too many tasks is not always a cause of stress, but it will be a source of stress if the number of tasks is not proportional to the ability both physically and skillfully and the time available to individuals. While the limited time in doing work can trigger stress because if someone who usually has the ability to complete the tasks assigned to him. Ability is related to expertise, experience, and time owned. Under certain conditions, employers often provide assignments with limited time. As a result, individuals are pursued time to complete tasks according to the time set by superiors.

Based on the results of the study showed that the majority of respondents as many as 36 people $(51.4 \%)$ had stress at a severe level. This can be seen from the frequency distribution of the questionnaire which shows that 25 respondents (35.72\%) answered frequently and always with questions I felt uncomfortable / did not match the housing facilities provided by the company, and as many as 14 people (20\%) answered frequently and always with questions I feel uncomfortable with the camp environment that is too many people.

According to other research, the absence of social support means that stress will tend to appear in individuals who do not get support from their social environment. Social support can be in the form of support from the work environment or family environment. Many cases show that individuals who experience work stress are those who do not receive support (especially morale) from their families, such as parents, in-laws, children, friends and the like. Likewise, when someone does not get support from their peers, they tend to be more susceptible to stress. This is caused by the absence of social support which causes inconvenience in carrying out their work and duties. ${ }^{11,12}$

Based on the results of the study it was found that there was a significant relationship between physical conditions and stress levels, where ( $\mathrm{p}$-value $=0.000$ $(<0.05)$ with $r=0.407)$. This study shows that the better the physical condition of the 
respondents, the lighter the stress level. This is in accordance with the opinion of Potter and Perry (2005) which states that one of the factors in the emergence of stress comes from within a person such as physical conditions, psychological conditions or emotional states. The extent to which the level of stress experienced by an individual on his illness is influenced by age and physical conditions and the severity of the disease he experiences. ${ }^{3}$

The results showed that there was a significant relationship between psychological burden and stress level (pvalue $=0.010(<0.05)$ and $r=0.305)$. This research shows that the lighter the psychological burden of the respondent, the lighter the stress level. This is in accordance with the opinion of others that a person's stress level is shown by one of the symptoms is psychological symptoms which include: anxiety, tension, confusion, anger, sensitivity, feelings, ineffective communication, boredom, job dissatisfaction, mental fatigue, loss of concentration.

The condition of respondents who are far apart from their families causes the burden of thought and psychological conflict in themselves to increase, family conditions that are not good can cause a person's condition to become stressed with the burden. This is shown by the psychological symptoms shown by the respondent, namely the results of research stating that the respondents feel anxious about the development of their children (54.28\%, $51.43 \%$ of their children's education), and the loyalty of their wives left in Indonesia $(31.43 \%)$

The results of the calculation of the Pearson correlation test show that there is no relationship between extreme weather and stress levels ( $p$-value $=0.252(<0.05)$ and $r=0.139$ ). Actually, based on the distribution of extreme weather questionnaires, it was found that $61.43 \%$ of respondents answered frequently and always felt uncomfortable with dust storms that often occur in Qatar, 55.72\% of respondents answered often and always felt insecure when traveling amid dust storms, $55.72 \%$ of respondents answered frequently and always felt the summer weather in Qatar was too hot for them, and $52.86 \%$ of respondents answered always and often felt the winter temperatures in Qatar were too cold for them. It could be that for extreme weather, respondents have adapted and are getting used to the temperature and climate in Qatar, so this extreme weather factor does not cause and cause stress for the respondents.

Based on the results of the study it was found that there was a significant relationship between workload conditions and stress levels, where ( $\mathrm{p}$-value $=0.001$ $(<0.05)$ with $r=0.379)$. This research shows that the lighter the workload of respondents, the lighter the stress level. The results of this study indicate $72.86 \%$ of respondents answered frequently and always extra carefully in doing their jobs, $45.72 \%$ of respondents answered often and always felt the work they were doing was full of danger/risk, and $41.43 \%$ of respondents answered often and always felt their superiors asked for work to be completed on time .

This result is in line with the research conducted by other research, the results of his research said that much of respondents experienced severe stress because of having a heavy workload, including distance from home to work, large responsibilities, and limitations and predetermined time targets trigger job stress on the office. ${ }^{13}$

Based on the results of the study it was found that there was a significant relationship between workload conditions and stress levels, where ( $\mathrm{p}$-value $=0.000$ $(<0.05)$ with $r=0.541)$. This research shows that the better the condition of the environment where the respondent lives, the lighter the stress level. The results of 
this study were based on noisy living conditions because the respondent's camp was inhabited by thousands of other workers, with a capacity of 8 workers from various ethnic groups placed in one room. In addition, psychological conditions are also very susceptible to misunderstandings among camp residents, and even fights and fights are reported often occurring in the respondent's neighborhood. This result is in accordance with the research conducted by others, the results of his research say that several of respondents said that the conditions of their work environment were stressful for their work. Lighting conditions that are lacking, there is noise in the work environment, and a high psychological work environment is the factors that trigger the stress of their work.

\section{CONCLUSION}

Based on the results of the above research with existing limitations, it is necessary to give advice to various parties. For health services Messaieed Medical Center Qatar is expected to provide counseling services about stress and stress work, how to understand the level of stress experienced, and how to deal with or reduce stress independently. Health services, especially nurses, are also expected to provide interactive health education and counseling about stress, how to seek help when dealing with stress, and how to modify conditions to reduce the risk of stress. The education provided is mainly about stress, handling, and prevention for every worker who shows symptoms of stress when visiting health services where he works. For companies that employ migrant semi skill workers to modify conditions that have the potential to cause stress. For Indonesian people in Messaieed Qatar to increase their knowledge about stress, handling and prevention, and to know where to look for help when there are community members or friends who show stress symptoms in their place. Suggestions for the Indonesian government to pay more attention to the education level of workers who will be sent abroad. Because a person's education level is very influential on a person's ability to deal with and manage the stress they experience. The recommendations for further researchers should be able to examine the respondent characteristic variables, especially added characteristics of ethnicity or citizenship other than Indonesia, where the results can be used as a comparison, whether there are significant differences regarding the level of stress experienced by semi-skilled migrant workers by citizens other than Indonesia.

\section{CONFLICTS OF INTEREST}

The author declares that none of him had any conflict of interests.

\section{REFERENCES}

1. Powell TJ, Enright SJ, Enright SJ. Anxiety and Stress Management [Internet]. Routledge; 2015 [cited 2019 Jun 21]. Available from: https://www.taylorfrancis.com/books/97813 15683867

2. Sarafino EP, Smith TW. Health psychology: biopsychosocial interactions [Internet]. [cited 2019 Jun 21]. 542 p. Available from: https://books.google.co.id/books?hl=id\&lr=\&i $\mathrm{d}=$ ypODBgAAQBAJ\&oi=fnd \&pg=PR6\&dq=Healt h+Psychology:+Biopsychosocial+Interaction\&o ts $=17 \mathrm{pLjG0HeV \& sig=EWlhgkwnJxCYwdeClmI}$ $\mathrm{mYbHQbeM \& redir \_ esc}=\mathrm{y} \# \mathrm{v}=$ onepage $\& \mathrm{q}=$ Healt h Psychology\%3A Biopsychosocial Interaction $\& \mathrm{f}=$ false

3. Potter, P. A., Perry, A. G., Stockert, P., \& Hall A. Fundamental of Nursing E-Book. Elsevier; 2016.

4. Watson R, Gardiner E, Hogston R, Gibson H, Stimpson A, Wrate R, et al. A longitudinal study of stress and psychological distress in nurses and nursing students. J Clin Nurs [Internet]. 2009;18(2):270-8. Available from: http://www.ncbi.nlm.nih.gov/pubmed/19120 753

5. Lee I, Wang HH. Perceived occupational stress and related factors in public health nurses. J Nurs Res [Internet]. 2002;10(4):253-60. Available from:

http://www.ncbi.nlm.nih.gov/pubmed/12522 
738

6. Yanto A, Rejeki S. The Related Factors To Decreased The New Graduate Nurses Work Stress Level In Semarang. Nurscope J Penelit dan Pemikir Ilm Keperawatan [Internet]. 2017 Dec 1;3(2):1. Available from:

http://jurnal.unissula.ac.id/index.php/jnm/art icle/view/2266

7. Singh RG. Relationship between occupational stress and social support in flight nurses. Aviat Sp Env Med [Internet]. 1990;61(4):349-52. Available from: http://www.ncbi.nlm.nih.gov/pubmed/23399 71

8. Nelson DL, Burke RJ. Gender, work stress, and health. 1st ed. Washington, D.C.: American Psychological Assoc.; 2002. xii, 260 p.

9. Adriaenssens J, De Gucht V, Maes S. Determinants and prevalence of burnout in emergency nurses: A systematic review of 25 years of research. Int J Nurs Stud [Internet]. 2015;52(2):649-61. Available from: http://www.sciencedirect.com/science/article
/pii/S0020748914002983

10. Greenberg JS. Comprehensive stress management. 13th ed. New York, NY: McGrawHill; 2013. xii, 444 p.

11. Xie Z, Wang A, Chen B. Nurse burnout and its association with occupational stress in a crosssectional study in Shanghai. J Adv Nurs [Internet]. 2011;67(7):1537-46. Available from:

http://www.ncbi.nlm.nih.gov/pubmed/21261 698

12. Cooke L. Conflict and challenging behaviour in the workplace. J Perioper Pr [Internet]. 2006;16(8):365-6. Available from: http://www.ncbi.nlm.nih.gov/pubmed/16939 162

13. Gevers J, van Erven $\mathrm{P}$, de Jonge J, Maas M, de Jong J. Effect of acute and chronic job demands on effective individual teamwork behaviour in medical emergencies. J Adv Nurs [Internet]. 2010;66(7):1573-83. Available from: http://www.ncbi.nlm.nih.gov/pubmed/20492 019 